\title{
Timetable-Less Travelling-Will It Steam Ahead, or Hit the Buffers?
}

\author{
Ruimin Deng \\ Faculty of Business Administration, South China University of Technology, Guangzhou, China \\ Email: ruimindeng@163.com
}

How to cite this paper: Deng, R.M. (2018) Timetable-Less Travelling-Will It Steam Ahead, or Hit the Buffers? Journal of Service Science and Management, 11, 497-509. https://doi.org/10.4236/jssm.2018.115034

Received: August 14, 2018

Accepted: October 7, 2018

Published: October 10, 2018

Copyright $\odot 2018$ by author and Scientific Research Publishing Inc. This work is licensed under the Creative Commons Attribution International License (CC BY 4.0).

http://creativecommons.org/licenses/by/4.0/

\begin{abstract}
Innovation in public transportation is considered an environment-friendly solution for growing demand. With regard to making the most use of existing infrastructure, Dutch rail sector is launching transport policy innovation "timetable-less travelling" which is defined as a set of tools, both hardware (physical) and software (algorithms or procedures). Innovation adoption is affected by numerous factors which asked for a systematic perspective. With the societal impacts framework and Success and Failure Factors (SFF) analysis, we form a clearer idea of the future of timetable-less travelling innovation.
\end{abstract}

\section{Keywords}

Timetable-Less Travelling, Public Transportation Innovation, Success and Failure Factors (SFF), Innovation

\section{Introduction}

Innovations can be seen everywhere nowadays. The fact that transportation is a sector with a large impact on both economic- and social performance, as well as on environmental performance, leads it to being a continuously changing and progressing environment. Most innovations in this sector are developed as a creative response to problems and imbalances emerging in the process of economic development or driven by the observations of new technological opportunities. Another big driver of innovations in transport has been the excitement and necessity of contributing to a sustainable transportation [1]. Innovations can be radical or incremental. Here, radical means that innovations are completely new (technological) artifacts and radical in nature [2]. "Incremental", on the other hand, is a term for innovations that focuses more on slightly improving the existing product, service, or processes [3].

There are considerable opportunities for technological innovation, both radi- 
cal and incremental in achieving a better and more sustainable transport system. Behavioral change will however be of equal importance in reaching these goals, which can be achieved with innovations in transport policy. There are many policy measures that can contribute to these goals. One of the approaches is promoting the use of the more sustainable modes of transport such as public transportation. By making public transport easier to use, it is expected to be more attractive. A better quality of the service is thus expected to result in a higher number of train-travelers, thereby contributing to more sustainable mobility. That is exactly the goal that the Government of the Netherlands has set for itself [4].

The Ministry of Infrastructure and Water management has set the goal in 2028 for the improvement of train services. The proposed policy to achieve this is called timetable-less travel (in Dutch: SpoorboekloosReizen). This policy includes that there will be 6 intercity trains and 6 sprinters every hour on the busiest rail routes in the country and there will be additional rail capacity for freight transport. This is necessary to accommodate the growing number of train travelers and the growth of rail freight transport. Furthermore, this enables the rail mode to better compete with other modes of transport. The central idea of the policy measure for passengers is that the traveler no longer needs a timetable to find a train: they always arrive in a few minutes before the trains arrive (referred to timetable-less travelling). As a result, rail travel will become more attractive to the passengers. The decision thus represents a choice for sustainable mobility.

The fruitfulness of "timetable-less travelling" as an innovative transport policy certainly depends on the societal impacts it has, and on some success and failure factors [5] [6]. There are plenty of studies focusing on technological innovations of railway transformation. Furthermore, there are studies discussing the effectiveness of policy measures. To the best of our knowledge, there are however, no studies that clearly answer what the societal impacts of such transport policy innovations are, and moreover, what factors influence the success and failure of such transport policy. The aim of this paper is therefore to analyze the societal impacts of the proposed innovation and to determine the Success and Failure Factors (SFF). The following two research questions concerning the successful of "timetable-less travelling" are central to this paper:

What SFF will determine the implementation of timetable-less travelling?

And

What are the societal impacts of timetable-less travelling for different relevant actors?

With the insight of these two questions, we develop the theory in policy innovation evaluations and provide an analysis model for public transportation and innovation and fill the gap of the research on policy innovation in theoretical aspect. In empirical aspect, this paper evaluated the feasibility of the timetable-less travelling project and provided the guidance for the implementation of future projects. 
In order to answer these research questions, firstly a theoretical background will be provided on the societal impacts of transport innovations, and then a conceptual framework will be composed, based on frameworks for SFF of transport innovations. In chapter 3 , an overview of the results of analyses is provided. Finally, Section 4 gives some concluding remarks and directions for further research.

\section{Theoretical Framework}

\subsection{Impacts of Transport Innovation}

Transport innovations can result in negative side-effects. Traffic jams, oil dependency, global warming, traffic safety and noise nuisance are all examples of externalities, which are results of transport activities [7]. However, they are also directly the effect of historical innovations in transport, given the fact that all current technologies are the result of innovations in the past [8]. It is generally said that heading off a problem before it happens is a more proactive practice rather than to solve it after all is burned out [9]. Hence, innovations that are assessed on their impacts and implications in advance are more likely to manage and mitigate all future risks in the market.

The studies to date about transport innovations have thus mostly focused on the policy-making matters, designing, visioning, and solving existing problems rather than on the impacts of the transport innovation itself [10]. Though anthropologists often relegate technological innovations to very minor roles as stimuli toward social evolution and power inequities, archaeological analyses of long-term cultural change cannot afford to ignore the many social, symbolic, and practical implications of major innovations in transportation [11]. This current literature gap should be pointed out to prevent new innovations from becoming new sources of problems and to access the fail and success factors of the innovations. It is thus of vital importance to get a good understanding of the impacts it will have. Furthermore, different actors might experience different impacts. Impacts assessments often focus on a narrow set of impacts on a particular group of people and hence significant impacts may be overlooked or undervalued [12]. It is thus important to distinguish between all relevant actors that are impacted by the innovation. With the fact that no one has done similar research previously, we need to identify more impacts structured with a causal-relations impacts diagram, that will be fully described later based on literature review.

\subsection{Success and Failure Factors}

Sustainable transport is challenging to achieve [13]. The success or failure of innovations depend on a number of factors such as the willingness of people to use them, changes in regulations and investments that need to be made [14]. It is thus a complex process that, if to be analyzed, has to be at the societal level, taking all relevant aspects into account. The implementation of a transport policy 
can be analyzed by the use of frameworks, as they can "alert policy makers to the variables that can be manipulated to improve the delivery of public services" [15]. In this chapter, a conceptual framework will be presented based on existing theory concerning the societal success and failure factors, which will function as a basis to do the SFF analysis.

Since we are looking at innovations in the area of sustainable transport, that is, innovations that reduce in one way or another the environmental impact of transport activities (in this case: less car use as a result of better public transport), we will be looking at existing frameworks of success and failure factors that were introduced in literature in the context of transport policy.

The basis of the conceptual framework developed is the framework of Feitelson and Salomon [14] on the adoption of transport innovations. The paper identifies feasibility as the key concept for implementation of policies. It distinguishes three different types of feasibility: technical feasibility, political feasibility and social feasibility. Respectively these categories of feasibility exemplify; if it can work technically, if it is supported by a wide coalition of specific interests, and if the majority of voters are likely to support it.

The concept of feasibility used by Salomon \& Feitelson [14] is however too narrow to capture the complexity of the concept of policy implementation, and is therefore extended. The starting point for the extension is based on the article of Van den Bergh [16]. The paper distinguishes 5 categories of factors that impact the implementation of innovation namely:

- Technological factors: (e.g., availability and complexity of the required knowledge and expertise, availability of complementary technologies, compliance with technical standards).

- Administrative and legal factors: (e.g., compatibility with current regulation, fitting in with existing procedures, consistency with legislation, and (lack of) clarity about division of responsibilities and competencies).

- Political and process related factors: (e.g., existence/lack of necessary institutions to implement the innovation effectively or efficiently, the role of interest groups, the distribution of political power, and the time horizon (shortversus long-term) of politicians).

- Socio-cultural and psychological factors: (e.g., involvement in and affinity with the project on the part of the stakeholders, perceived risks and interests of firms, consumers and civil servants, and degree to which drivers and passengers are asked to change their behavior).

- Economic factors: (e.g., net benefits for market agents, availability of funding and subsidies, possible lock-in due to increasing returns to scale, expected influence on (international) competitive position, possibility of "free rider" behavior, and expected influence of the project on the regional and local economy (jobs)).

Every category can thus contain both success and/or failure factors. In the proposed conceptual model these will thus form the basis to determine feasibility, resulting in five different types of feasibility. 
Vonk Noordegraaf [6] also extended the framework of Salomon \& Feitelson [14], because it states that "the framework does not give insight in how actors appraise these feasibility aspects and how this appraisal can change over time" [6]. The paper adds the theoretical concepts of policy opportunity, and political decisiveness to the framework, because the original framework only considers feasibility, which it views as not sufficient enough to ensure successful policy implementation.

The outcome is thus a framework consisting of three elements: policy actors' appraisal of the feasibility, the opportunity to put a policy on the policy agenda, and the political decisiveness needed for the adoption of a policy instrument.

\subsection{Conceptual Framework}

Combining these insights leads to the following conceptual framework for determining implementation as shown in Figure 1. Base on the feasibility analysis on adoption of transport innovations by Feitelson and Salomon [14], we develop three layers to access the timetable-less traveling policy, which is constituted by

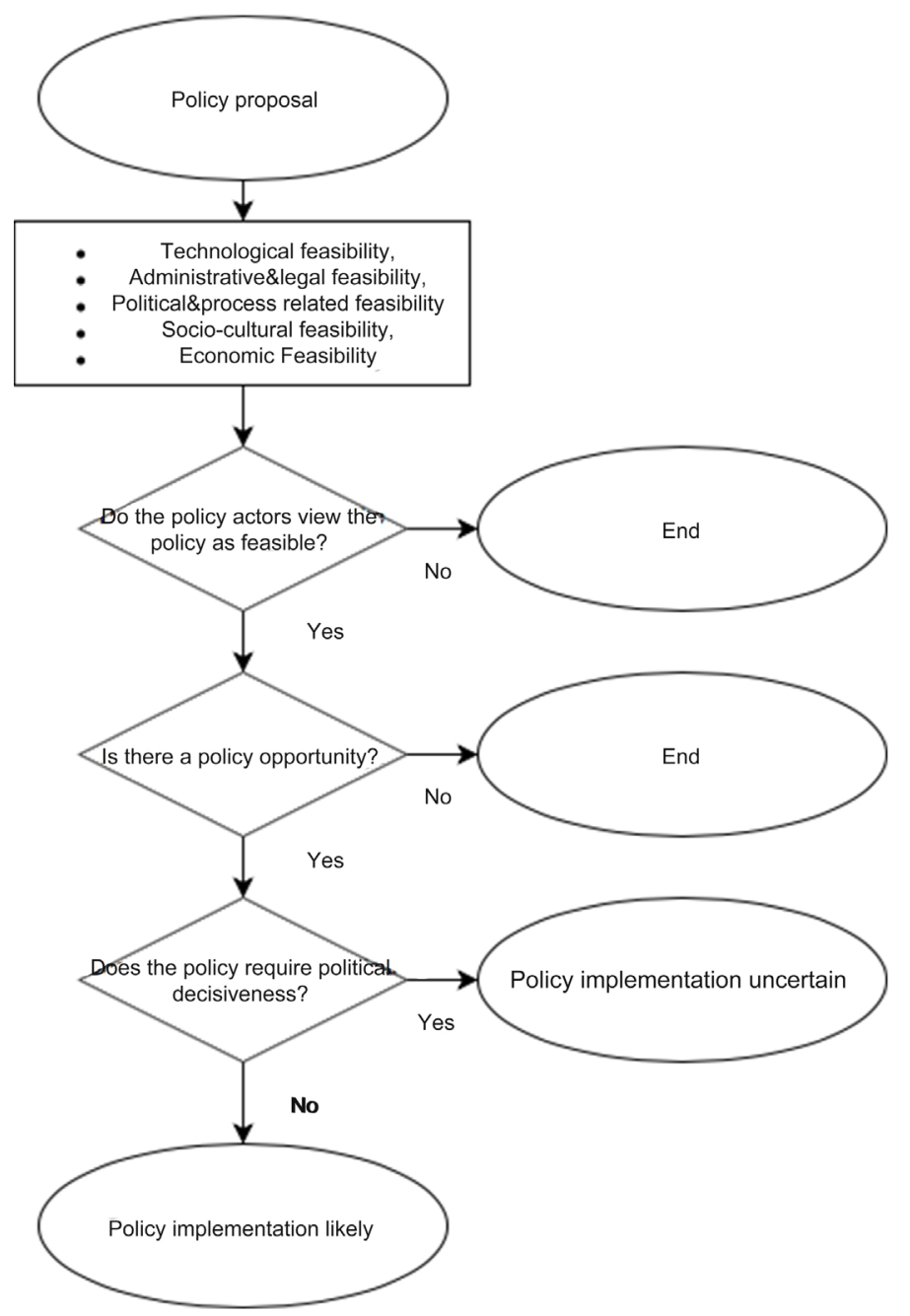

Figure 1. Conceptual framework. Source: adapted by author. 
three question: "Do the policy actors view the policy as feasible?", "Is there a policy opportunity?”, "Does the policy require political decisiveness?”.

\section{Analysis and Results}

\subsection{Societal Impacts Analysis}

As can be seen in Figure 2, the policy of timetable-less travel has several consequences. One of those consequences is an increase in the number of passenger trains running, since the frequency is upped. This increase will lead to more passenger trips made by train. This increase has several causes. Firstly, due to the higher frequency of the trains, the average waiting times (and transfer times) will decrease, which will enhance the number of passenger trips made by train. Secondly, the chance of having a seat in the train increases (due to the increased capacity), which might lead to more people opting for the train as well. However, as a consequence of more passengers using the train, the chance of an available seat decreases after a while. This interdependency is shows by introducing a

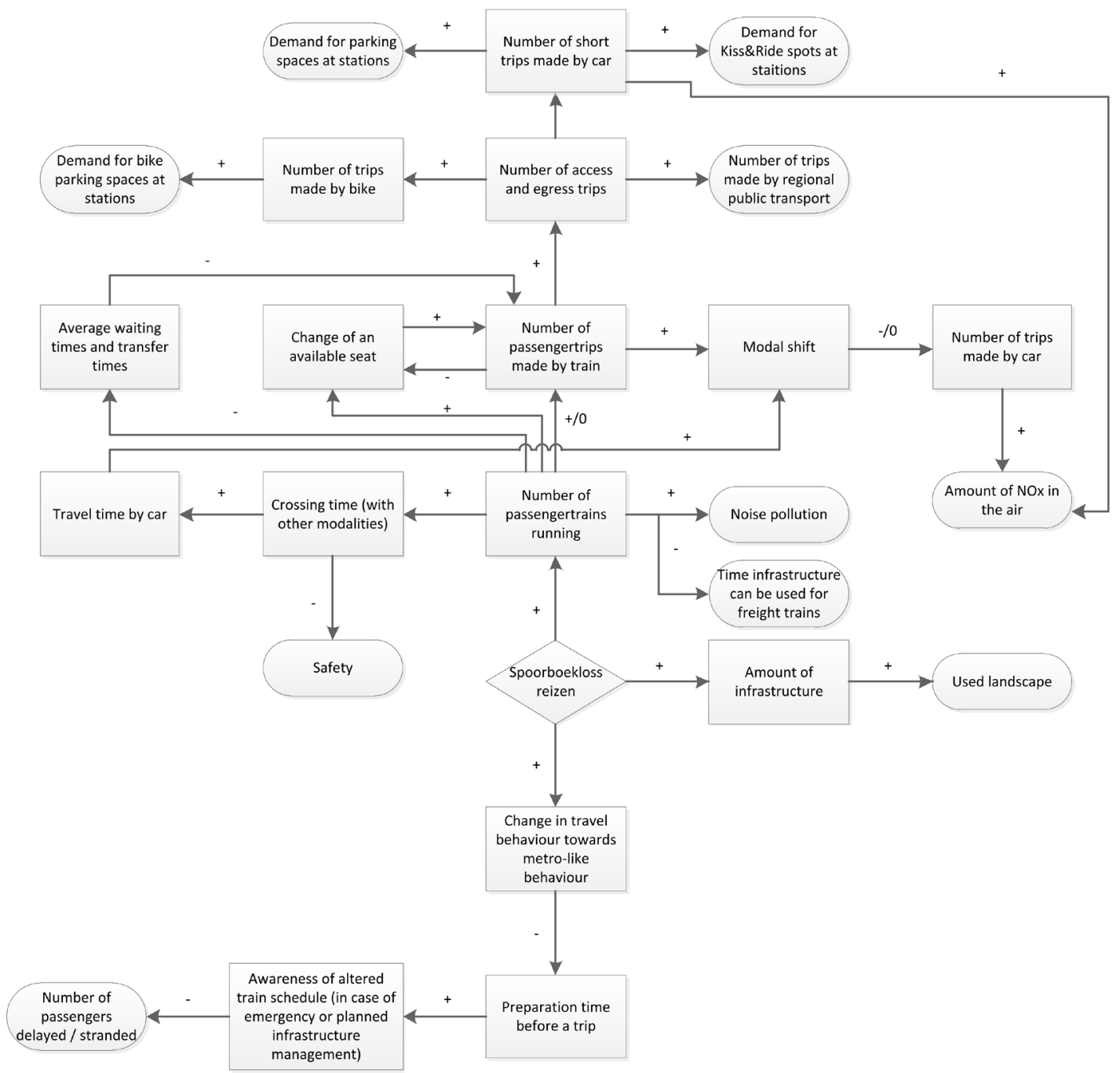

Figure 2. Impact assessment timetable-less travelling. 
feedback loop in Figure 2. And lastly, supply attracts demand, but it is questionable to what degree this still applies in this case, since underlying factors have been distinguished that might explain this phenomenon.

This increase in number of passenger trips performed by train results in a change in the modal shift and, assuming people will not travel more, it also leads to a decrease in the number of trips made by car. This decrease in car trips will lead to less car emissions, like NOx in the air.

The increase in the number of trips made by train also increases the need for access and egress trips. This increase in access and egress trips leads to an increase in the number of trips made by regional public transport and to an increase in the number of trips made by bike/foot (and possibly short car trips). The increase in trips performed by bike leads to an increase in demand for the number of bike parking spaces needed (and the possible increases in short car trips lead to an increase in the demand for car parking spots).

Furthermore, the increase in the number of operating passenger trains leads to more noise pollution and to less availability of the infrastructure for container trains to a longer occupation time (per unit of time) of the crossings with other modalities [17]. This increase in occupation time might lead to less safety due to for instance impatient other modality users who will take more risks to cross the crossing while the signals already indicate that a train is approaching [18]. Additionally, the increased occupation of the crossings will lead to larger travel times by car, because they will, on average, have to wait longer before they can cross the railway. This increase in car travel time might lead to a modal shift.

Secondly, the implementation of SpoorboekloosReizen will lead to more infrastructure to accommodate the increased frequency [19]. The extra infrastructure will take up some landscape.

Lastly, the policy is also aimed at changing the behavior of the travelers in such a way that they will act more like metro (or subway) users. This change in behavior will lead to less preparation time before a trip, since travelers know that they will not have to wait more than ten minutes (just like the metro system). However, the decrease in preparation time will also lead to less awareness of altered train schedules due to for example planned infrastructure management or accidents resulting in an alteration of the schedule. This in turn ensures that more passengers will be delayed or even stranded.

All these relations are represented in Figure 2. A positive relation means that when one factor increases, the other increases as well (or they both decrease). A negative relation indicates an inverse relation, meaning that one increases when the other decreases and vice versa.

\subsection{Implications for Different Actors}

SpoorboekloosReizen, as a public transport project, involves multiple stakeholders, including the Dutch government, enterprises and the public. Examples thereof are for instance the Ministry of I \& W, railway related companies like the 
NS and ProRail, other public transport providers (tram/bus) like the RET, citizens living nearby rails, train commuters and car commuters. In Appendix A, a stakeholder analysis can be found which explains their interests and all potential impacts per actor category.

Using the stakeholder analysis framework (see Figure 3) to classify stakeholders based on their power and influence and interest-related level, we identified four key players who are both high in interest and power lever and have significant influence on the implementation of timetable-less travelling. They are Ministry of I \& W, NS, Suppliers (materials \& ICT) and Train commuters.

Any social change initiative or any policy project needs for strategic and tactical reasons to get an inventory of institutions involved, identify the key players, assess potential support or opposition among them [20]. For example, NS, the passenger railway operator, is responsible for providing the transport on a commercial basis. The NS needs to update their software and hardware facilities, like staff arrangement or scheduling ICT facilities to meet the need of timetable-less travelling for the sake of safety and operation. This means that the project needs to reach a certain occupancy rate to meet the financial targets of NS, or more government subsidies is needed from Ministry of I \& W. Ministry of I \& W, the governmental agency for improving mobility in the Netherlands, is the policy decision maker and founder of timetable-less travelling. They need to gain the public support for the policy and raise money for the expense of railway company. To gain the support of the public, train commuters should benefit from the project and get a safer, cost-saving, more reliable, sustainable train service. In a word, the implementation of timetable-less travelling requires a close cooperation of key players. We should focus on the key players group, engage and consult with regularly.

\subsection{Success and Failure Factors}

As shown in paragraph 2.3 (Conceptual Framework), certain criteria have to be

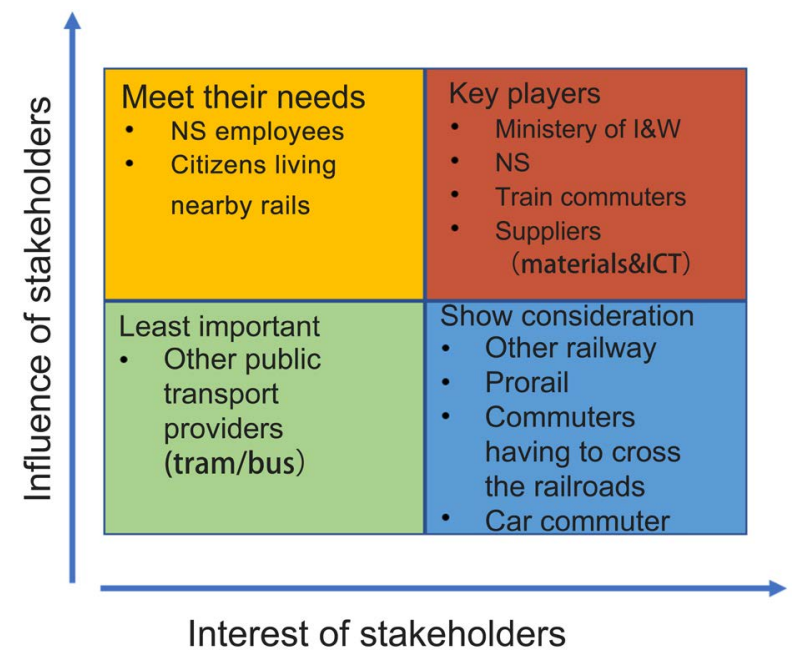

Figure 3. Stakeholder analysis matrix. 
met in order for the policy to be implemented. The first criterion that has to be met is the feasibility component of the policy. In total five feasibilities will be examined.

\subsubsection{Is the Policy Feasible?}

\section{1) Technological feasibility}

The first feasibility of SpoorboekloosReizen (timetable-less travel) policy that will be discussed is the technological feasibility. Regarding this feasibility, the main question is whether the policy can be implemented with current technology that is at hand. The European Rail Traffic Management System (ERTMS) with its different levels ensures that trains will be able to follow-up each other at closer distances (due to a smaller safety duffer, because of the use of moving blocks instead of fixed blocks), which allows more trains to run on the existing infrastructure [21]. Furthermore, ProRail is building extra infrastructure on the traces where the capacity of the existing infrastructure isn't sufficient [19].

\section{2) Administrative \& Legal feasibility}

Another feasibility that must be considered is the administrative and legal feasibility. This includes for instance the need for a clear division in the responsibilities and legal responsibilities of the government regarding the safety of its inhabitants. As mentioned in the previous paragraph, ERTMS allows trains to have shorter headways without causing a decrease in safety [22]. Regarding the clear division, the policy doesn't force a change in the current division of the rail management in the Netherlands. This means that the current division, with ProRail being responsible for the infrastructure management and (mostly) NS for the operation of the trains, remains the same. In addition, both NS and ProRail remain accountable to the ministry of Infrastructure and Water management [23] [24] [25].

\section{3) Political and process related feasibility}

Thirdly, the political and process related feasibility of the proposed policy will be discussed. An important aspect of this feasibility is the existence (or lack) of the needed organizations. As partly discussed in the previous paragraph as well, there are two parties in play in the Dutch railway management. These are ProRail and NS and they cover the infrastructure management and operations. This means that the needed organizations are already in play. Furthermore, when taking a close look at the timetable for the implementation of this policy, it is clear that the policy of timetable-less travel is aimed at the long-term, since the first government piece dates from 2008 and the policy should be implemented before 2029. Since this is a time-span of 21 years in total, the policy is aimed at the long-term [19].

\section{4) Socio-cultural and Psychological feasibility}

The second to last feasibility that will be considered is the socio-cultural and psychological feasibility of timetable-less travel. One of the factors to consider here is the support of the public. Train commuters will most likely support this policy, since they will encounter less waiting time on average for example. On 
the other hand, users of other modalities, primarily the car, might be less enthusiastic about this, since they might encounter longer travel times, because the crossings will be occupied more often [18]. However, the increase in the occupation rate is not always (very) large [17]. Another aspect of this feasibility is how much the users are requested to change their behavior in order to let the policy be a success. Even though the policy is partly aimed at changing the behavior of the train passengers, the policy doesn't need the users to change in order to let the policy be a success. If the train users still look up the train schedules, they still encounter less waiting time than before the policy since the frequency is upped. The only difference is that they don't have less waiting time at the stations, but at home (hidden waiting time) [26].

\section{5) Economical feasibility}

Finally, the economical feasibility is taken into accounts. In order to determine if the policy is economically feasible, the Social cost-benefit analysis has been consulted. This analysis shows that the timetable-less travel policy is economically feasible in five of the six considered scenarios. Additionally, the negative cost-benefit ratio on the one negative scenario isn't very large (0.94) [27].

Although there are a few potential downsides to some actors, like some commuters in the remote areas could spend more time than usual because of the train scheduling. The policy Increase traffic capacity on rush hour and make greater use of train infrastructure, which in total make more benefit for the public. Considering all these factors, it is concluded that the proposed policy of timetable-less travel is feasible.

\subsubsection{Is There a Policy Opportunity?}

A policy opportunity occurs when there is a coupling between a problem that is urgent for most actors, a solution that can be supported and participants that are inclined to make a decision [6].

Sustainability is high on the policy agenda in the Netherlands, and there is a widespread agreement on the urgency of the issue [19]. Policy decisions are also influenced by the goals set on European level, and the climate agreement of Paris that the Netherlands has signed. As the policy is a choice for sustainable mobility, the urgency of the policy is thus clear. The ministry of Infrastructure and Water management has indicated that it will invest $€ 6.2$ billion in the coming year in its infrastructure, indicating that solutions can be supported [26]. As the policy "timetable-less travelling" is a proposal of the ministry, one can say that they are definitely inclined to make a decision. It can thus be concluded that there is a policy opportunity.

\subsubsection{Does the Policy Require Political Decisiveness?}

Timetable-less travelling can be considered an incremental innovation, since there are no radical new ways of doing things involved. This means that it is not a complex innovation, and no long transition times are needed to implement it. Due to this, there is no political decisiveness needed. This means that imple- 
mentation is likely.

\section{Conclusions}

In this paper, we've analyzed an innovative transport policy measure called "timetable-less travelling". To date, research has failed to address all the societal impacts of transport innovations, and therefore, new problems have continued to come into existence. Furthermore, the success or failure of innovations is often poorly understood. The aim of the papers therefore was to answer the research questions: What are the societal impacts of "timetable-less travelling" for different relevant actors? And: What success and failure factors will determine the implementation of timetable-less travelling? In order to answer these research questions, a theoretical background study was performed to indicate the relevance of addressing societal implications, and a conceptual framework was composed to describe the success and failure factors of the transport policy measure.

From the societal impact analysis, it can be concluded that although there are many positive impacts resulting from the innovation, such as more seats available, more attractive public transport and a more sustainable transport system, there are also negative impacts to be taken into accounts. These range from more noise pollution, longer crossing times and reduced safety at the crossings. It is thus important to consider and prevent or reduce these consequences when implementing the transport policy. Furthermore, some other effects need to take into accounts, such as the increased demand for bicycle parking places, and induced demand for regional public transportation. Failure to address these issues can result in a (perceived) failure of the innovation, and therefore, it is important to be aware of this.

From the appliance of the conceptual framework of success and failure factors, it can be concluded that the policy is likely to be implemented. On all dimensions of feasibility, the policy measure is regarded as feasible. Furthermore, there is a clear policy opportunity, and the measure does not require political decisiveness.

\section{Conflicts of Interest}

The author declares no conflicts of interest regarding the publication of this paper.

\section{References}

[1] Taalbi, J. (2017) What Drives Innovation? Evidence from Economic History. Research Policy, 46, 1437-1453. https://doi.org/10.1016/j.respol.2017.06.007

[2] Kahn, K.B. (2018) Understanding Innovation. Business Horizons, 61, 453-460. https://doi.org/10.1016/j.bushor.2018.01.011

[3] World Bank Group (1970) Radical and Incremental Innovation. https://www.innovationpolicyplatform.org/content/radical-and-incremental-innova tion

[4] Rijksoverheid (2018). Ministerie van Infrastructuuren Waterstaat. 
https://www.rijksoverheid.nl/ministeries/ministerie-van-infrastructuur-en-watersta at

[5] Geels, F.W. (2004) From Sectoral Systems of Innovation to Socio-Technical Systems: Insights about Dynamics and Change from Sociology and Institutional Theory. Research Policy, 33, 897-920. https://doi.org/10.1016/j.respol.2004.01.015

[6] Vonk Noordegraaf, D. (2016) Road Pricing Policy Implementation. Delft University of Technology, Netherlands.

[7] Wee, B.V., Annema, J.A. and Banister, D. (2013) The Transport System and Transport Policy: An Introduction. Edward Elgar, Cheltenham, UK.

[8] Christensen, C.M. (2013) Innovator's Dilemma. Perseus Books.

[9] Myler, L. (2015) Innovation Is Problem Solving ... And a Whole Lot More. https://www.forbes.com/sites/larrymyler/2014/06/13/innovation-is-problem-solving -and-a-whole-lot-more/

[10] Hickman, R., Saxena, S., Banister, D. and Ashiru, O. (2012) Examining Transport Futures with Scenario Analysis and MCA. Transportation Research Part A: Policy and Practice, 46, 560-575. https://doi.org/10.1016/j.tra.2011.11.006

[11] Arnold, J.E. (2010) Transportation Innovation and Social Complexity among Maritime Hunter-Gatherer Societies. American Anthropologist, 97, 733-747. https://doi.org/10.1525/aa.1995.97.4.02a00150

[12] Litman, T. (2002) Evaluating Transportation Equity. World Transport Policy \& Practice, 8, 50-65.

[13] Banister, D. (2008) The Sustainable Mobility Paradigm. Transport Policy, 15, 73-80. https://doi.org/10.1016/j.tranpol.2007.10.005

[14] Feitelson, E. and Salomon, I. (2004) The Political Economy of Transport Innovations. Transport Developments and Innovations in an Evolving World. Springer, Berlin Heidelberg.

[15] Meter, D.S.V. and Horn, C.E.V. (1975) The Policy Implementation Process: A Conceptual Framework. Administration \& Society, 6, 445-488.

https://doi.org/10.1177/009539977500600404

[16] Van den Bergh, J.C.J.M., Leeuwen, E.S.V., Oosterhuis, F.H., Rietveld, P. and Verhoef, E.T. (2007) Social Learning by Doing in Sustainable Transport Innovations: Ex-Post Analysis of Common Factors behind Successes and Failures. Research Policy, 36, 247-259. https://doi.org/10.1016/j.respol.2006.11.001

[17] Gelderland, O. (2017) Spoorbomen minder langdicht dan verwacht. https://www.omroepgelderland.nl/nieuws/2144426/Spoorbomen-minder-lang-dicht -dan-verwacht

[18] $\mathrm{AD}$ (n.d.) Elke 10 minuteneen intercity! In Vughtworden ze ergek van. https://www.ad.nl/binnenland/elke-10-minuten-een-intercity-in-vught-worden-zeer-gek-van a58046ea/

[19] Rijksoverheid (2018) Aanpassingen Trajecten Spoorboekloos Reizen. https://www.rijksoverheid.nl/onderwerpen/spoor/spoorboekloos-reizen/trajecten-s poorboekloos-reizen-phs

[20] Aligica, P.D. (2006) Institutional and Stakeholder Mapping: Frameworks for Policy Analysis and Institutional Change. Public Organization Review, 6, 79-90. https://doi.org/10.1007/s11115-006-6833-0

[21] ETRMS (n.d.). http://www.ertms.net/?page_id=42

[22] Koning, J.A. (2002) Comparing the Performance of ERTMS Level 2 Fixed Block and 
ERTMS Level 3 Moving Block Signalling Systems Using Simulation Techniques. https://www.witpress.com/elibrary/wit-transactions-on-the-built-environment/61/8 9

[23] NS (n.d.) Verantwoordelijkheden over NS.

https://www.ns.nl/over-ns/de-spoorsector/verantwoordelijkheden.html

[24] ProRail (n.d.) Organisatie. https://www.prorail.nl/wie-zijn-we/organisatie

[25] Rijksoverheid (2018) Afspraken Rijksoverheid met NS enProRail. https://www.rijksoverheid.nl/onderwerpen/openbaar-vervoer/afspraken-rijksoverhe id-met-ns-en-prorail

[26] Nielsen, O.A. (2000) A Stochastic Transit Assignment Model Considering Differences in Passengers Utility Functions. Transportation Research Part B: Methodological, 34, 377-402. https://doi.org/10.1016/S0191-2615(99)00029-6

[27] ECORYS Nederland BV (2010) Maatschappelijke Kosten-Batenanalyse Programma Hoogfrequent Spoorvervoer.

https://www.ecorys.nl/sites/default/files/Ecorys\%20\%282010\%29\%20Maatschappelij ke\%20Kosten-Batenanalyse\%20Programma\%20Hoogfrequent\%20Spoorvervoer.pdf 